\title{
A Minimal Invasive Technique in the Treatment of Mucocele in 5 Year Girl: A Case Report
}

\author{
Kavitha $\mathrm{K}^{1}$, Pallavi Pujar ${ }^{2}$, Praveen Kumar Mandroli ${ }^{3}$
}

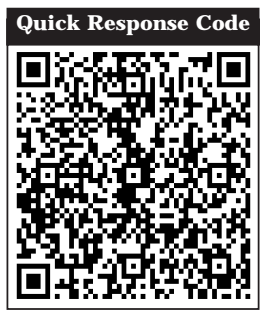

doi: $10.5866 / 2016.8 .10123$

${ }^{1}$ Senior Lecturer

Department of Pedodontics,

Coorg Institute of Dental Sciences,

Virajpet, Coorg, Karnataka.

${ }^{2}$ Senior Lecturer

${ }^{3}$ Professor \& Hod

Department Of Pedodontics,

Maratha Mandal's Dental College,

Belgaum, Karnataka.

\section{Article Info:}

Received: April 12, 2016

Review Completed: May 11, 2016

Accepted: J une 10, 2016

Available Online: September, 2016 (www.nacd.in) (C) NAD, 2016 - All rights reserved

\section{Email for correspondence:}

kavithakanthraj19987@gmail.com

\section{ABSTRACT:}

Among the benign lesions involving the oral cavity, mucocele is a common lesion of the oral mucosa that results from an alteration of minor salivary glands due to a mucous accumulation. Mucocele involves mucin accumulation causing limited swelling. Mucoceles can appear at any site of the oral mucosa where minor salivary glands are present. Diagnosis is principally clinical; therefore, the anamnesis should be carried out correctly, looking for previous trauma. Treatment frequently involves surgical removal. Nevertheless micro marsupial ization, cryosurgery, steroid injections and $\mathrm{CO} 2$ laser are also described. Micro marsupialization being a non-invasive option to treat mucoceles in pediatric dentistry owing to its simplicity, fewer complications involved and as well that it's well-tolerated by patients. Presented here is the case with mucocele of lower lip in a 5 year old girl treated with micro-marsupialization a minimal invasive technique with complete healing of the lesion in 18 months without recurrence.

Key words: micro-marsupialization, mucocele, mucocele treatment.

\section{INTRODUCTION}

Among the benign lesions involving the oral cavity are the mucus retention phenomena, lesions that involve the salivary glands and their respective ducts. Clinically, these lesions may be classified as mucocele or ranula. Mucocele consists of a volumetric increase caused by the accumulation of mucus inside the tissues. The ranula is a form of mucocele specifically localized on the floor of the mouth. ${ }^{1}$ On the basis of their microscopic characteristics, these lesions are classified as mucus retention or mucus extravasation cysts, the former being characterized by the presence of epithelial tissue and the latter, which have been reported to occur at higher frequency, by a covering with granulation tissue. ${ }^{2-4}$ The major etiologic factor is related to trauma which provokes rupture and/or occlusion of the excretory duct of the salivary gland involved, leading to extravasation and accumulation of salivary mucus inside connective tissue. ${ }^{5}$ 
These lesions preferentially occur among white people of both sexes, with a slight predominance among females. ${ }^{2,6}$ With respect to age, they mainly occur during the second and third decades of life. ${ }^{3}$ The preferential localization of mucocel eis thelower lip, but it may also be found on the tongue, palate, and buccal mucosa. 2, 3,5 The lesions can be located directly under the mucosa (superficial mucocele), in the upper sub mucosa (classic mucocele), or in the lower corium (deep mucocele). They usually occur singly and only very rarely bilaterally. Clinical presentation depends on the depth of the lesion, while the color depends on the size and its nearness to the surface. Superficial mucocele; the mucus accumulates immediately bel ow the mucosa, resulting in small translucent vesicles $(0.1-0.4 \mathrm{~cm}$ in diameter) in the soft palate, the retromolar region, and the buccal mucosa. In time, these blisters burst spontaneously or by trauma, leaving shallow ulcers or erosions. The Classic MC size varies from a few millimeters to several centimeters in diameter, but $75 \%$ of thelesions are smaller than $1 \mathrm{~cm}$ in diameter. Eventually, the surface of the lesion turns irregular and whitish due to multiple cycles of rupture and healing caused by trauma or puncture. ${ }^{7}$ The lesions have a sessile or pedicled base and are of flaccid or fibrous consistency. They have clearly defined limits and a smooth surface. Evolution is rapid or slow and painless, with periods of remission and exacerbation. ${ }^{5}$ Prognosis is favorable and several treatments have been proposed in the literature, such as excision of the lesion associated or not with removal of the gland involved, marsupialization, cryosurgery, laser and micromarsupialization.

Redish reported that the placement of a wire suture through the lesion is a method of treatment that may be utilized for ranulas. ${ }^{8} \mathrm{M}$ orton and Bartley stated that ranula can betreated with the placement of a silk suture into the dome of the cyst. ${ }^{9}$ The silk suture technique was named micromarsupialization by Cardoso in 1974, and considered a choice for treating mucoceles. A suture was passed through thelesion and it was maintained for at least 10 days. ${ }^{10}$ Castro indicates the micromarsupialization technique for mucoceles with more than $1 \mathrm{~cm}$ in size and for ranulas. ${ }^{5}$ The present case report of mucocele of lower lip was intervened by miromarsupialization technique with uneventful healing.

\section{CASE REPORT}

A five year old girl reported to the Department of Pedodontics and Preventive Dentistry, Maratha Mandal's Dental college and research center, Belgaum, Karnataka, with chief complaint of swelling in the lower lip since 3 months. Parent gave history of remission and exacerbation of theswelling which gradually increase in size thereafter. Patient also had a positive history lower lip biting habit with its frequency increased by the presences of swelling.

On extraoral examination no abnormalities in lip was present. Intraoral examination revealed swelling on right side of the lower lip measuring about $1 \times 0.5 \mathrm{~cm}$ in diameter. The lesion was painless on pal pation, had clearly defined limits, surface was irregular and pink in color; sessile base and fibrous in consistency (Figure 1). Other hard tissue findings were pit and fissure caries with respect to 55 and 65. Glass ionomer restoration was done with respect to pit and fissure caries.

Based on the history and clinical examination, the lesion was diagnosed as mucocele. Considering the age of the child and presence of enough literature to support, miromarsupialization technique was preferred as the line of treatment.

The area was disinfected with a povidone iodine 0.1 solution; a topical anesthetic was applied over the entire lesion for approximately $3 \mathrm{~min}$, and a 3.0 silk suture was passed through the internal part of the lesion along its widest diameter (Figure 2). The suture thread was then passed through the lesion, and a surgical knot was made, leaving a space between the knot and the lesion. The mucocele was then compressed, and the accumulated saliva extravasated around the suture (Figure 3). The sutures were removed after 10 days post operatively.

Clinical analysis of the region involved by the lesion after treatment by this technique suggested no deformity occurred in the area after passage of the suture, and no pain or infectious processes was reported. Follow-up was done since the performance of the technique every six months; total period took 


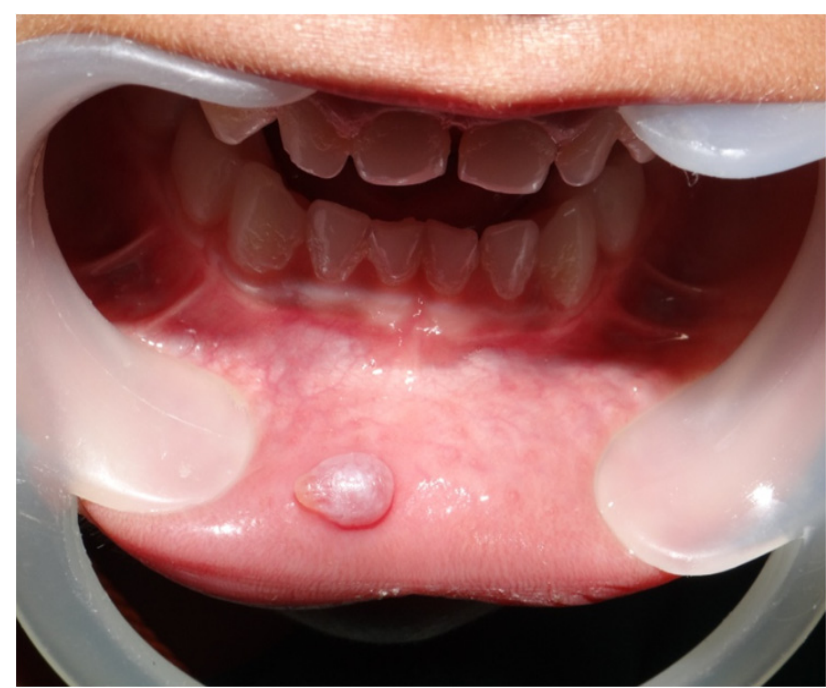

Figure 1: I ntraoral photograph showing mucocele in the right side of lower lip

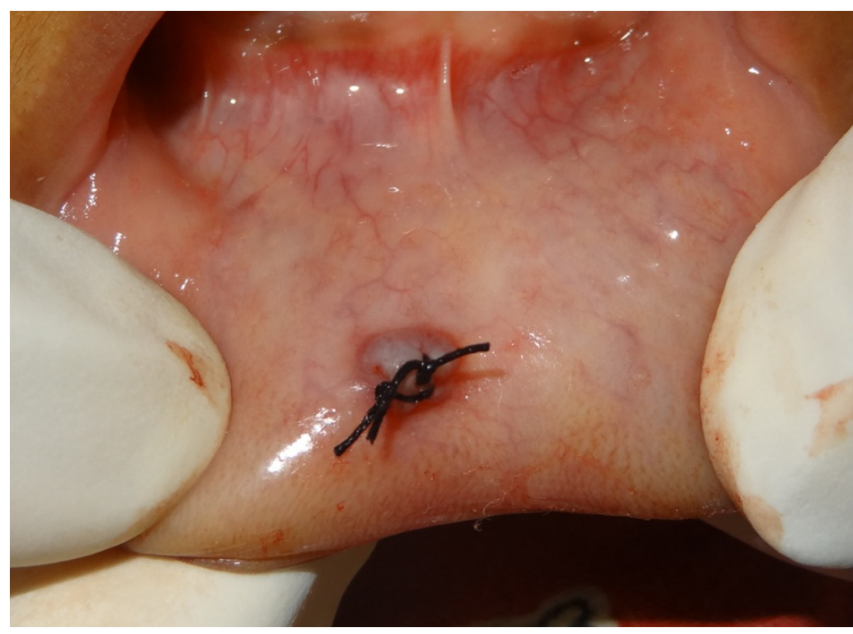

Figure 3: Surgeon's knot placed and reduced the size of the lesion

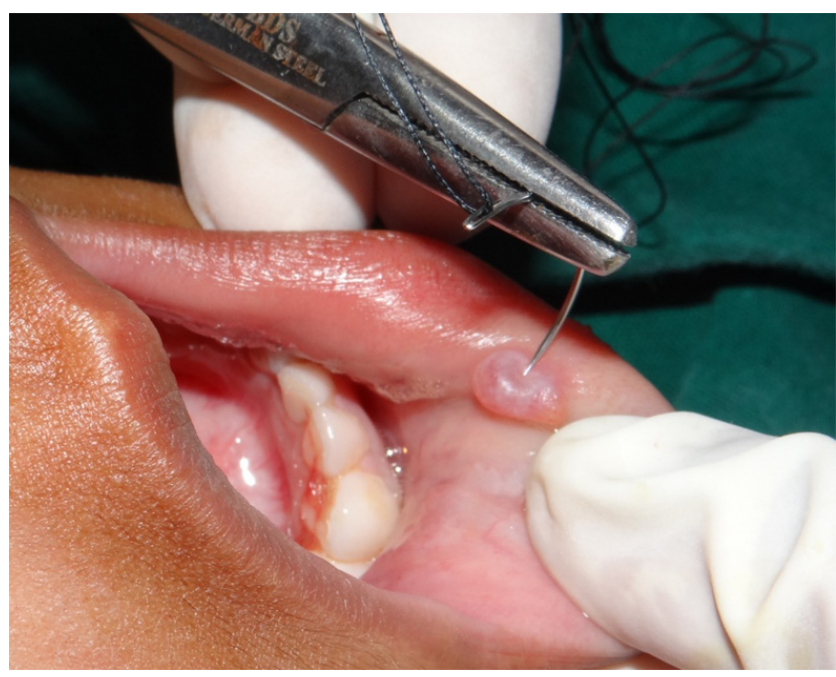

Figure 2: Passing the silk suture through the widest diameter of the lesion

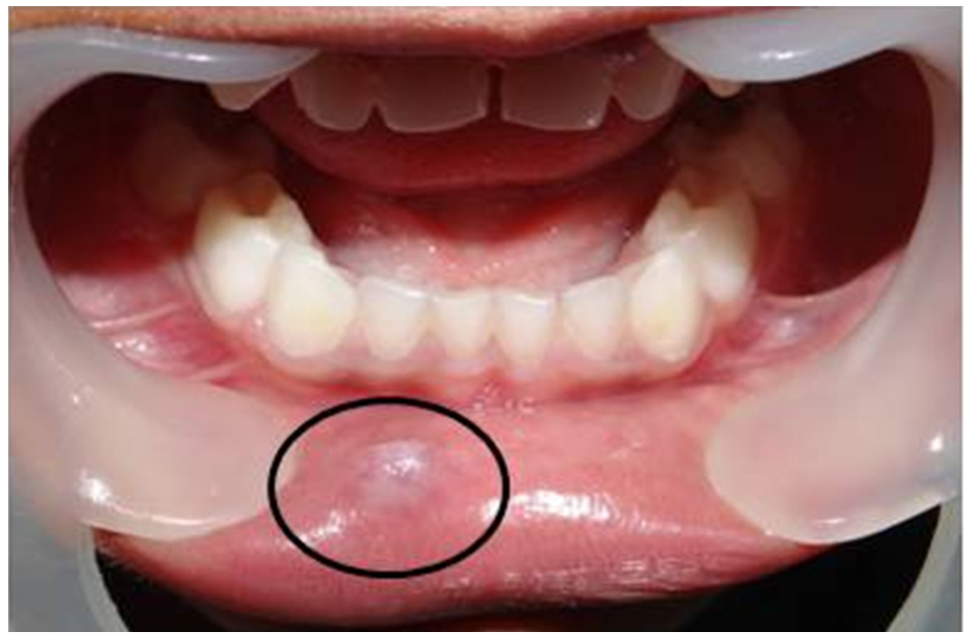

Figure 4: Six months follow-up showing reduction in size and change in the surface irregularity

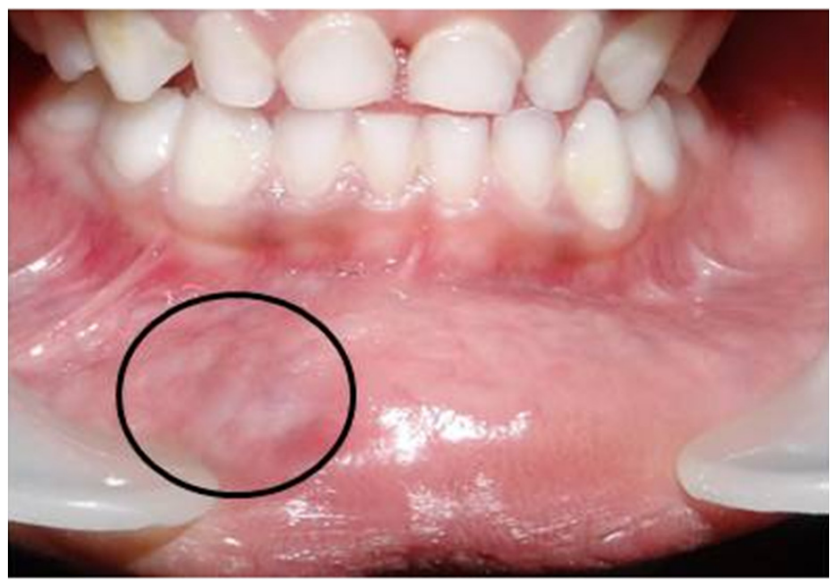

Figure 5: Eighteen months follow-up showing complete healing of the lesion 
18 months for complete healing of the lesion (Figure 4 and 5).

\section{DISCUSSION}

The micro-marsupialization technique was selected because it is of simple execution, less traumatic, and well tolerated by the patient. These are fundamental features to be considered in pediatric dentistry. Simple incision and drainage will result in recurrence of mucus retention phenomena. ${ }^{11}$ The introduction of a suture presumably maintains a tract while permitting an epithelial tract to form between the surface and the underlying salivary glandular tissues. ${ }^{12}$

Information from the history is very important in diagnosis. Questions concerning trauma in the lower lip and the presence of periods of remissions should be performed. The observation of the characteristics of the lesion during clinical examination is of extreme importance for a successful treatment, otherwise unsuccessful outcomes are frequent. Although salivary gland neoplasms in childhood and adolescence are rare, especially in the minor salivary glands, the micromarsupialization technique is contraindicated for lesions located in palate and buccal mucosa, because of the possibility of a clinical misdiagnosis and a missing benign or malignant salivary gland tumor that are more frequently found in those areas. ${ }^{13-16}$

An important factor observed during the execution of the technique is that only topical anesthesia over the lesion needs to be applied, a fact that greatly favors cooperative behavior on the part of children. The mucus content of the lesion is the reason there is only need to anesthetize the mucosa that covers the lesion. According to Holst \& Evers, a two-minute application time of the topical anesthetic on the oral mucosa is adequate for best performance. ${ }^{17}$

It was observed that immediate extravasation of mucus with the passage of the suture and consequently reduction of the lesion in volume. This is a fundamental clinical characteristic for the diagnosis of mucus retention phenomena. If the extravasation does not occur, biopsy and histopathologic analysis are recommended.
Another feature is the passing of the suture through the interior of the lesion which, according totheliterature, causes epithelialization around the suture, establishing new excretory ducts and leading to the disappearance of the lesion. ${ }^{5,11,12,18}$ On this basis, it is suggested that the suture be passed through the widest diameter of the lesion in order to involve all the parts that compose it.

Morton and Bartley reported that the suture may come loose after 2 or 3 days and in this case treatment should be repeated which was observed in the present case. ${ }^{12}$ I nflammation of the area was noted in all cases after the removal of the suture. According to Racey et al, silk sutures produce inflammation after 7 days. ${ }^{18}$ The inflammation may be due to surgical trauma and accumulation of debris around the suture. Bacterial invasion of the suture track is possible, although, clinically, it was not observed in this patient. ${ }^{19}$ Sandrini et al has suggested that the sutures be maintained for 30 days, but further studies have shown that keeping sutures for such long periods in children will be a cause of discomfort and infection because of suboptimal oral hygiene. ${ }^{20}$

In pilot study done by Sagari et al, out of 8 cases $87.5 \%$ showed full resolution when treated with micro-marsupialization, whereas of 7 cases $57 \%$ showed full resolution when treatment was carried out by surgical excision. ${ }^{21}$ The cases that showed recurrence in both the groups were later treated by a surgical excision. Similar result was observed in the present case.

\section{CONCLUSION}

Although micro-marsupialization has been described in the literature since 2000, mainly for the treatment for ranulas, its use in the treatment for other mucoceles has been limited. The micromarsupialization technique as a treatment option instead of surgical excision in children has certain advantages such as no need of infiltrative anesthesia, shorter surgical time, shorter postoperative healing period, and patient's tolerance is better. These are fundamental features to be considered in pediatric dentistry. 


\section{REFERENCES}

1. Black RJ , Croft CB: Ranula: pathogenesis and management. Clin Otolaryngol 1989; 7:299-303.

2. Oliveira DT, Consolaro A, Freitas FJ G: Histopahological spectrum of 112 cases of mucocele. Braz Dent J 1993; 4:2936.

3. Shafer WG, Hine MK, Levy BM: Lesões físicas e químicas da cavidade bucal. In Tratado de Patologia Bucal. 4th Ed. Riode J aneiro: Guanabara, 1985, pp 512-515.

4. Yamasoba $T$, Tayama N, Syoji $M$, et al: Clinicostatistical study of lower lip mucoceles. Head \& Neck 1996; 12:316-320.

5. Castro AL: Glandulas salivares. In Estomatologia, 2nd Ed. Sao Paulo: Santos, 1995, pp 152-154.

6. Kang SK, Kim KS: Clinical and histopathologic study of salivary mucoceles. Taehan-Chikkwa-Uisa-Hyophoe-Chi 1989; 27:1059-1071.

7. P Lopez-J ornet. Labial Mucocele: A Study Of Eighteen Cases. The Internet J ournal of Dental Science 2005; 3:1-5.

8. Redish CH. Ranula: A report of two cases. J Indiana D A 1956; 35:9-12.

9. Morton RP, Bartley J R: Simple sublingual ranulas: pathogenesis and management. J Otolaryngol 1995; 24:253254.

10. Tommasi AF: Doenças das glândulas salivares. In Diagnóstico em patologia bucal, 1st Ed. Sao Paulo: Artes Medicas, 1982, pp 303-326.

11. Morton RP, Bartley J R: Simple sublingual ranulas: pathogenesis and management. J Otolaryngol 1995; 24:253254.

12. de Courten A, Lombardi T, Samson J : Pleomorphic adenoma of the palate in a child: 9-year follow-up. Int J Oral Maxillofac Surg 1996; 25:293-295.
13. Gustafsson $H$, Dahlqvist $A$, Anniko $M$, et al: Mucoepidermoid carcinoma in a minor salivary gland in childhood. J Laryngol Otol 1987; 101:1320-1323.

14. Loyola AM, de Araujo VC, de Sousa SO, et al: Minor salivary gland tumours. A retrospective study of 164 cases in a Brazilian population. Eur J Cancer B Oral Oncol 1995;197201.

15. Waldron CA, el-M ofty SK, Gnepp DR: Tumors of the intraoral minor salivary glands: a demographic and histologic study of 426 cases. Oral Surg Oral Med Oral Pathol 1988; 66:323- 333.

16. Holst A, Evers $\mathrm{H}$ : Experimental studies of new topical anaesthetics on the oral mucosa. Swed Dent 1985; 9:185191.

17. Selvig KA, Biagiotti GR, Leknes $K N$, et al: Oral tissue reactions to suture materials. Int J Periodontics Restorative Dent 1998; 18:474-487.

18. Racey GL, Wallace WR, Cavalaris CJ , et al: Comparison of a polyglycolic-polylactic acid suture to black silk and plaincatgut in human oral tissues. J Oral Surg 1978; 36:766770.

19. Selvig KA, Biagiotti GR, Leknes $K N$, et al: Oral tissue reactions to suture materials. Int J Periodontics Restorative Dent 1998; 18:474-487.

20. Sandrini FA, Sant'ana-Filho M, Rados PV. Ranula management: Suggested modifications in the micromarsupialization technique. J Oral Maxillofac Surg 2007; 65:1436-1438.

21. SK Sagari, KC Vamsi, D Shah, V Singh, GB Patil, S Saawarn. Micro - marsupialization: a minimally invasive technique for mucocele in children and adolescents. J Indian Soc Pedod Prev Dent 2012; 30:188-191.

\section{Gain quick access to our journal online View our journal at www.nacd.in}

